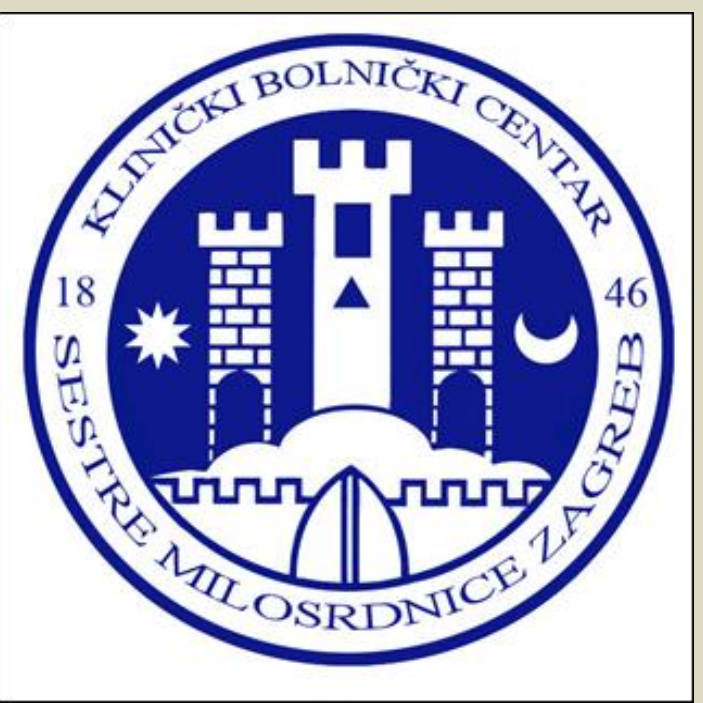

\title{
Spontaneous rib fracture in pregnancy- case report
}

Ida Marija Šola, Vesna Košec, Hrvojka Soljačić Vraneš, Senka Sabolović Rudman, Vesna Gall

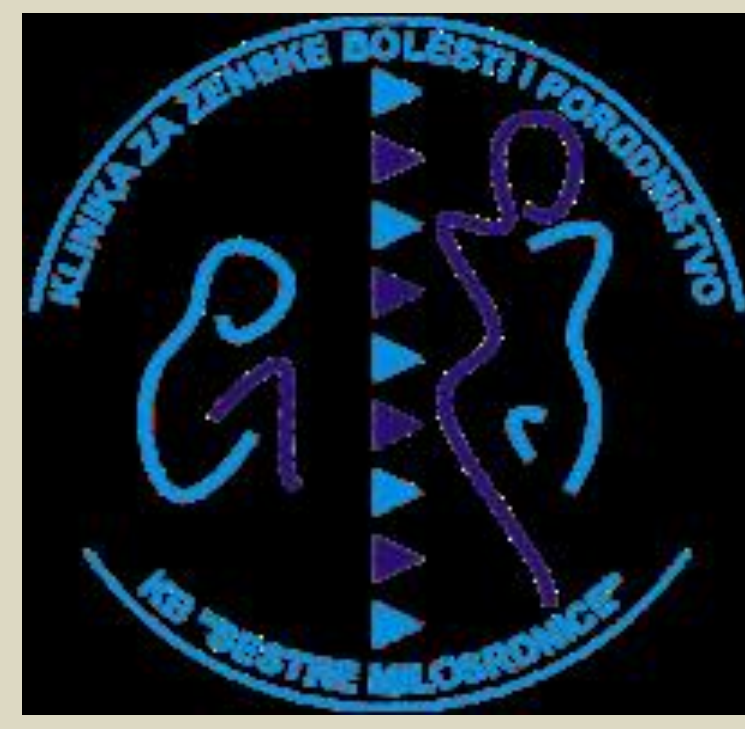

University hospital center Sestre milosrdnice, Zagreb, Croatia

There are few cases in literature that describe spontaneous bone fractures in pregnancy. Since it is a rare condition there is no recommended management during pregnancy and mostly includes individual approach. This condition can be challenging for obstetricians regarding the way of delivery and possible more trauma to sceletal part of pelvis during delivery.

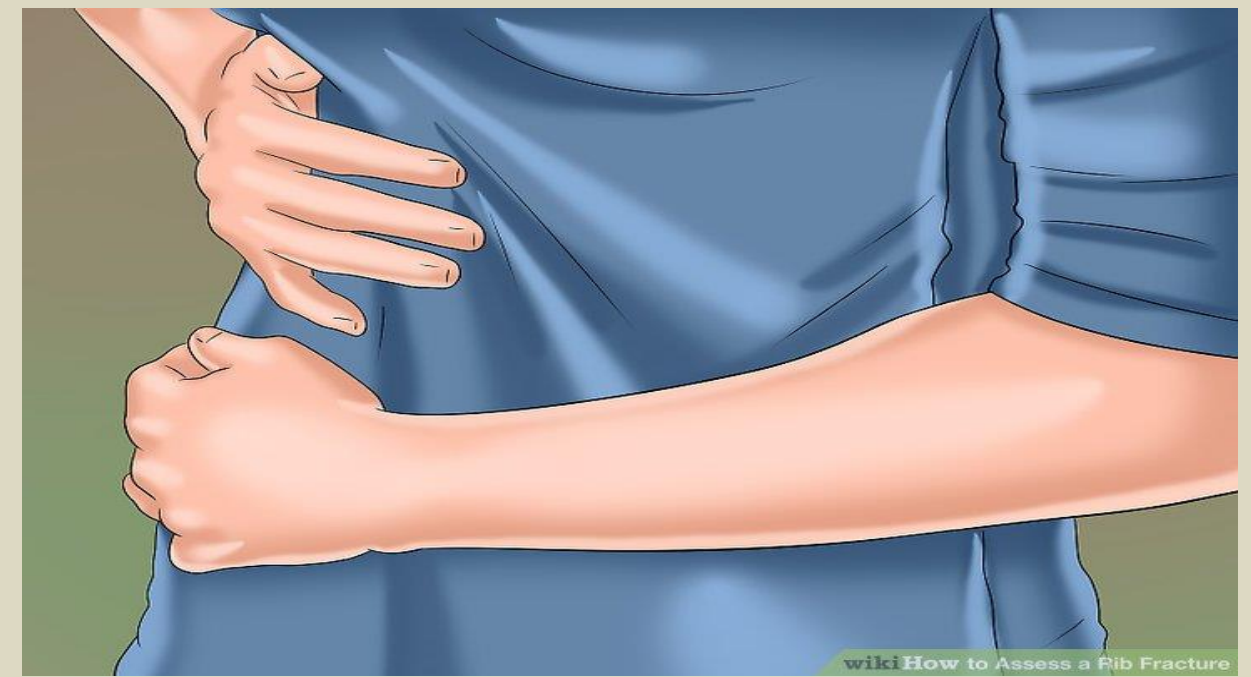

We present a case of 31- year old Caucasian secundiparous woman in week 34 of pregnancy who came to the physical therapy specialist because she woke up with acute left costal pain. After examination, the ultrasound was made and showed $8^{\text {th }}$ left rib fracture. Three days later after minimal movement, she experienced acute costal pain again, this time at the right side of thorax after which she came to Obstetrical unit in our Clinic. Ultrasound confirmed $8^{\text {th }}$ right rib fracture as well. In patient's medical history there were no fractures. She had idiopatic hyperprolactinemia for last three years without therapy. She had no headaches or vision problems and MRI of the head showed no pathology. There was no pathology in previous pregnancy, but patient reported sudden loss of four teeth in early postpartal period. There is no osteoporosis in family history.

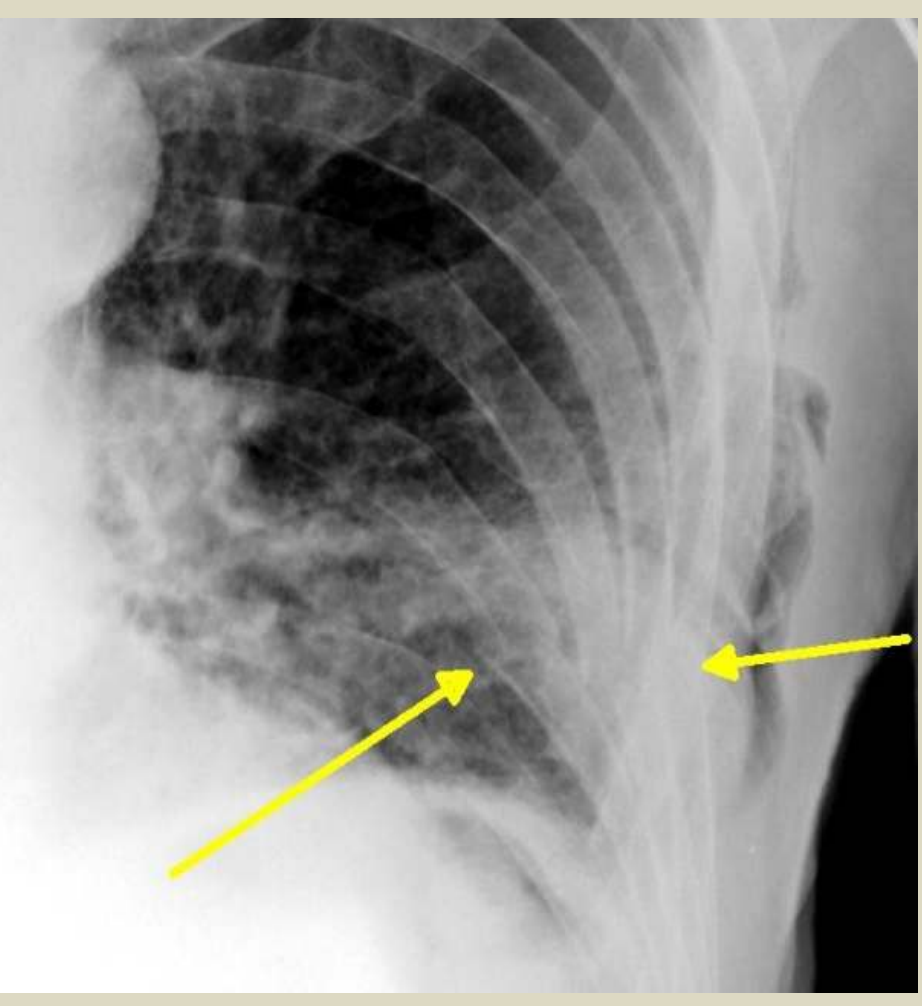

Due to the spontaneous bilateral rib fracture, laboratory test were done and showed normal calcium serum level- $2,22 \mathrm{mmol} / \mathrm{L}$ and also normal phosphorus level- $0,27 \mathrm{Mmol} / \mathrm{L}$, but hypercalciuria- $8,7 \mathrm{mmol} / 24 \mathrm{~h}$ was found. Patient's 25 -hydroxyvitamin D level was low- $43,3 \mathrm{nmol} / \mathrm{L}$ and parathyroid hormone was $4,1 \mathrm{pmol} / \mathrm{L}$ which is a normal level. Examination and normal levels of thyroid- stimulating hormone and cortisol ruled out hyperthyroidism and Cushing 's syndrome, and diagnosis of osteoporosis in pregnancy was designated.

Patient was treated with $\mathrm{CaCO} 3-1 \mathrm{~g}$ per day and D3 drops $4000 \mathrm{IU}$ till the end of pregnancy. She had spontaneous vaginal delivery. After that there were no more fractures in pregnancy, delivery or postpartum period.

Postpartal period teeth loss after first pregnancy could have been the first symptom of pregnancy induced calcium loss and should have been investigated during that time. Regardless to that if there is a pregnant patient with acute thoracic or spine pain, pregnancy associated osteoporosis should be suspected, especially if previous anamnestic data suggest the presence of risk factors. Immediate treatment is needed to avoid potential complications during the delivery.

\section{References}

Baszko-Błaszyk D., Horst-Sikorska W., Sowiński J. Pregnancy-associated osteoporosis manifesting for the first time during second pregnancy. Ginekologia Polska. 2005;76(1):67-69.

le Goff P., Saraux A. Ostéoporose de la grossesse. Revue du Rhumatisme. 2001;68(8):729-733. doi: 10.1016/s1169-8330(01)00166-1. Mourgeus C, Malochet- Guinamand S, Soubrirer M. Refractory reumatic disorder: atypical postpregnancy osteoporosis. Case Rep Rheumatol. 2015;2015:327965. doi: 10.1155/2015/327965.

Ozturk C., Atamaz F. C., Akkurt H., Akkoc Y. Pregnancy-associated osteoporosis presenting severe vertebral fractures. Journal of Obstetrics and Gynaecology Research. 2014;40(1):288-292. doi: 10.1111/jog.12157 